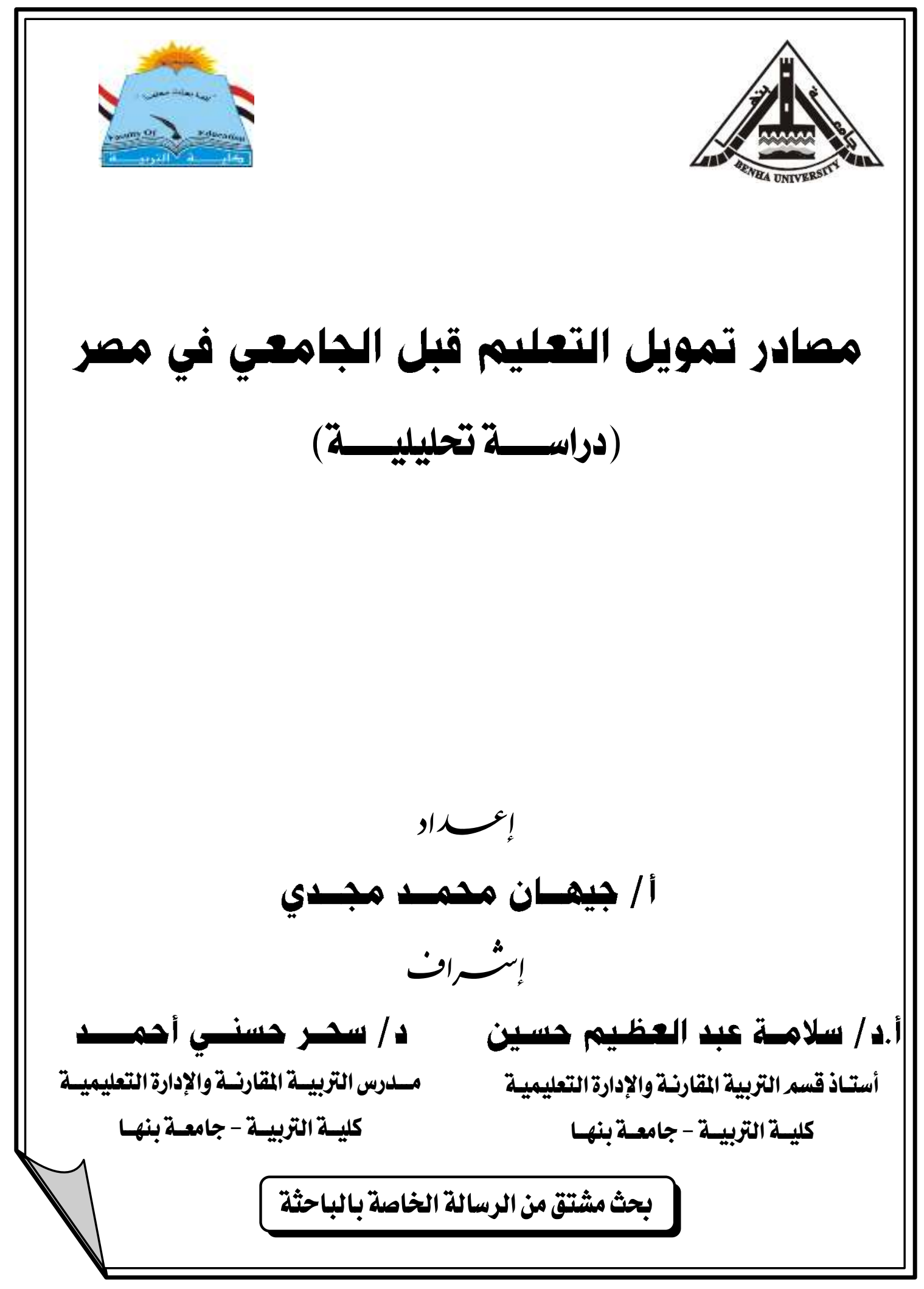




\section{مصادر تمويل التعليم قبل الجامعي في مصر}

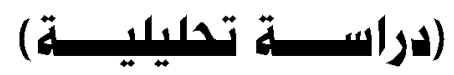

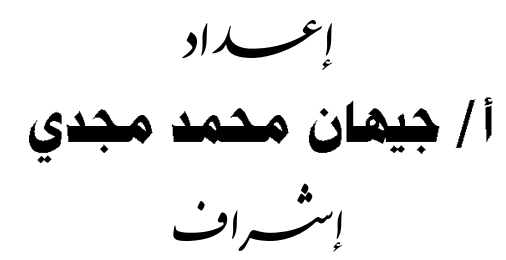

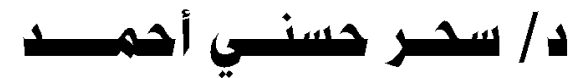

مــدرس التربيــة المقارنــة والإدارة التعليميـة

كليـة التربيـة - جامعـة بنهـا
أ.ده / سـلامسة عبد العظيم حسبين

أستاذ قسه التربية المقارنـة والإدارة التعليميـة

كليـة التربيـة - جامعـة بنهـا

\section{مستخلص البحث بالالغة العربية}

استهدفت الدراسة إلى التعرف على علي مصادر تمويل التعليم قبل الجامعي في مصر وكيفية الإستفادة منها لخدمة العملية التعليمية وذلك من خلال التعرف علي مصادر تمويل التعليم. والكثف عن مصادر جديدة للتمويل. والوقوف على واقع تمويل التعليم في مصر . لكى يحقق البحث أهدافه ويجيب عن تساؤلاته استخدم المنهج الوصفي.

$$
\text { وتكمن أهمية البحث في كونه: }
$$

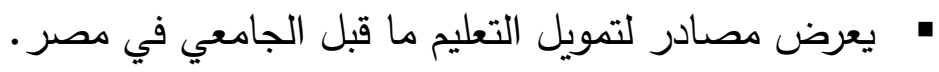
• التأكيد على أهمية مصادر التمويل كمدخل تطويري في التعليم.

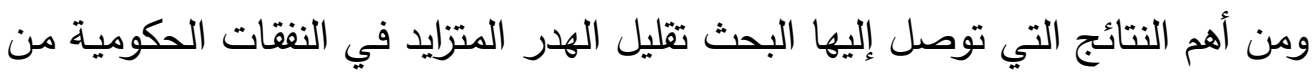
خلال إتباع أساليب حديثة في بناء المدارس من خلال إنشاء المدارس بنظم وتصميمات جديدة وتوظيف الخبرات في التصميم والتنفيذ وتجهيز المدارس، وإمكانية الوصول للمناطق النائية،

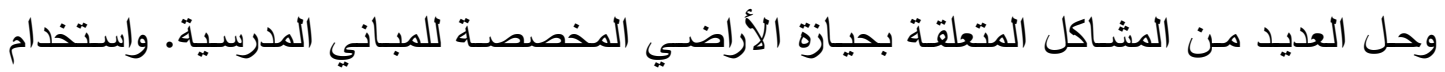
تكنولوجيا المعلومات المتقدمة في التدريس بما يعمل على تخفيض الكلفة التدريسية ـ الاهتمام

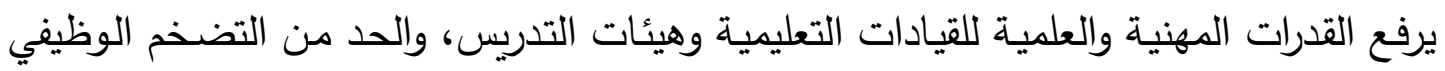

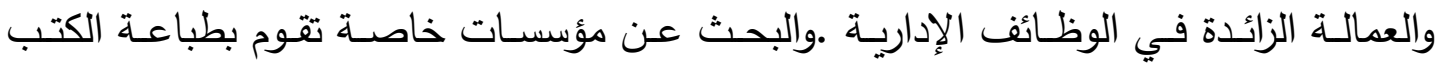
التعليمية تتافس فيما بينها لتقليل تكاليف الطباعة وتحسين جودة المنتج.و زيادة المخصصات بلات التصات المالية المخصصة للعملية التعليمية. 
إعتمد التقدم الاقتصادي في أي دولة من الدول على جودة مخرجات المنتج التعليمي

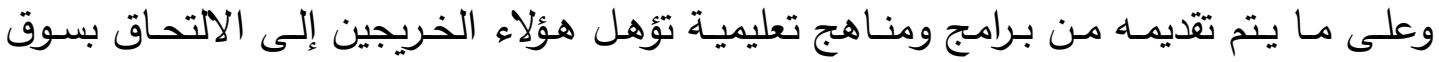

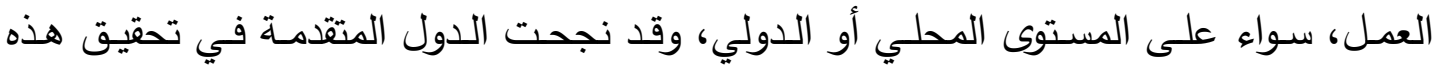

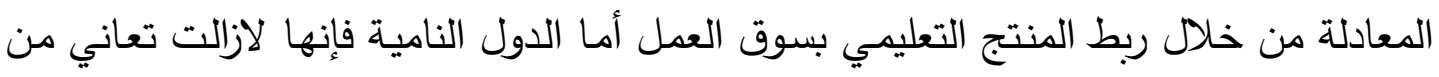

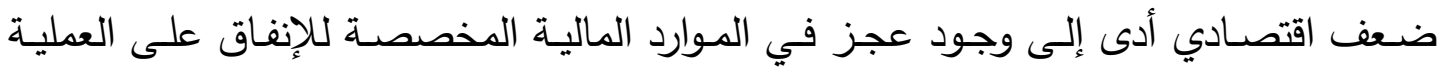

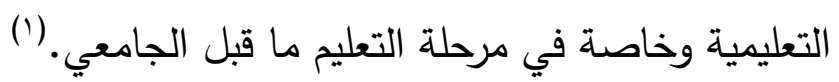

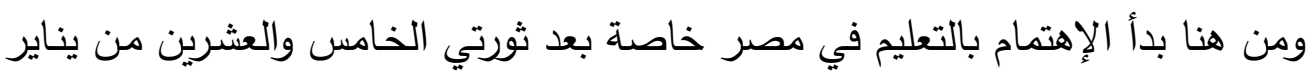

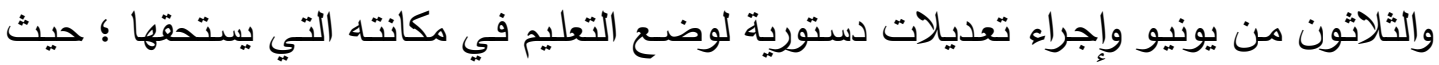

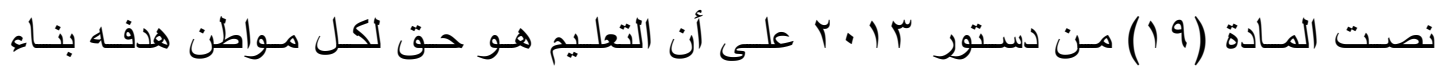

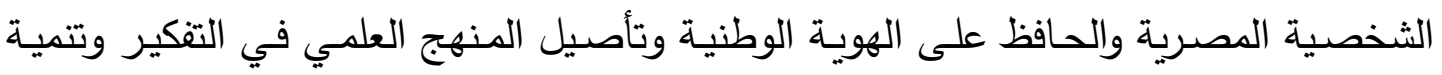

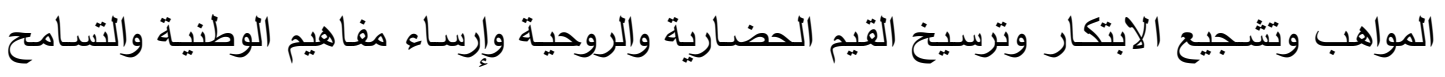

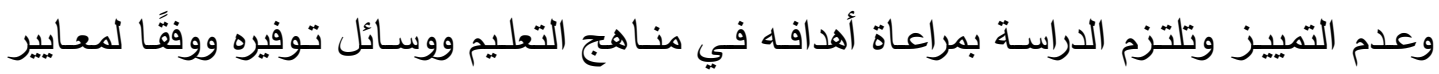
الجودة. (r) - (ب)

وفي هذا الصدد كان لابد من أن تهتم الدولة أيضًا بتحديد ميزانية الانفاق على التعليم

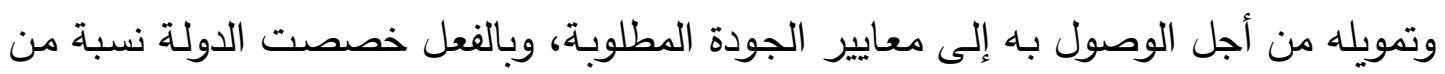

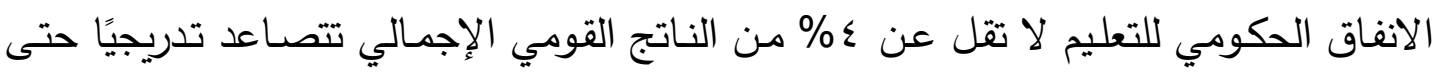

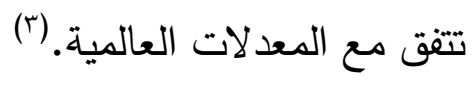

تواجه العملية التعليمية تحدياً كبيراً يتمثل فى تحسين جودة التعليم فى المراحل المختلفة،

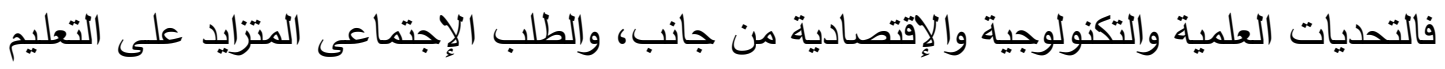

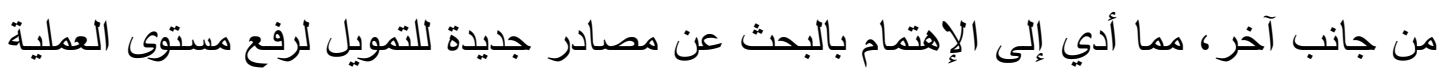

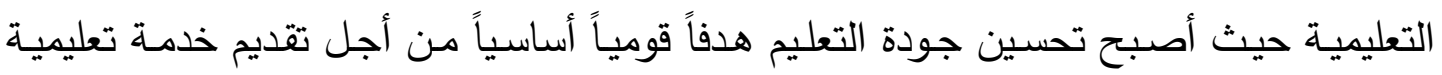

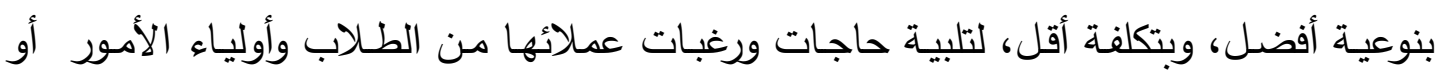

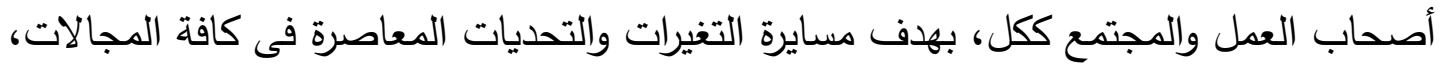

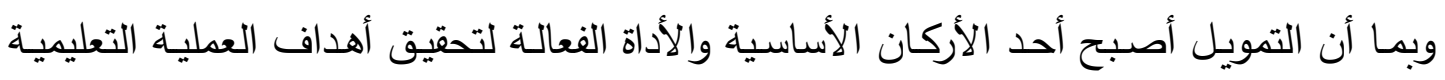


لكونه يمكن المؤسسات التعليمية من تحديد قدراتها المالية الحالية والمستقبلية بما يضمن لها النجاح فى عالم يتسم بالتعقيد والتغير المستمرين، لذلك بدأ الاهتمام البحث عن مصادر جديدة للتمويل واستثمارها بشكل فعال.

ومن ثم يمكن صياغة مشكلة البحث على النحو التالي:

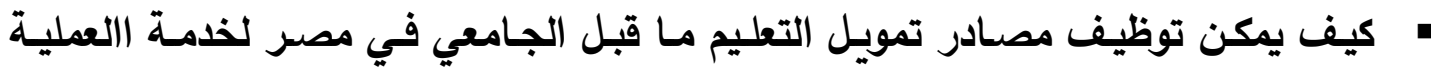

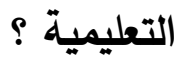
ويتفرع من هذا السؤال الرئيس التساؤلات التالية:

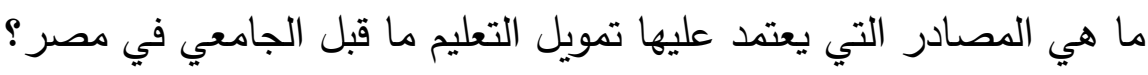

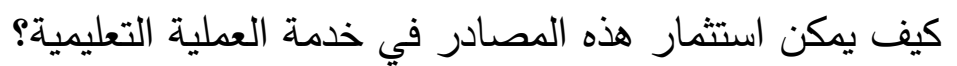

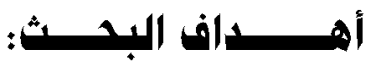

سعى البحث الحالى نحو التعرف علي مصادر تمويل التعليم قبل الجامعي في مصر وكيفية الإستفادة منها لخدمة العملية التعليمية وذلك من خلال: • التعرف علي مصادر تمويل التعليم. • الكثف عن مصادر جديدة للتمويل.

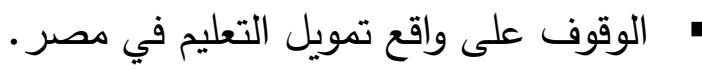

$$
\text { أهميــة البدث: وتكمن أهمية البحث في كونه: }
$$

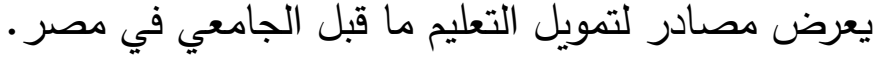
ا التأكيد على أهمية مصادر التمويل كمدخل تطويري في التعليم.

$$
\text { منهــــ البحث: }
$$

لكى يحقق البحث أهدافه ويجيب عن تساؤلاته استخدم المنهج الوصفي.

المحسـاور العلميسة:

• • مصادر تمويل التعليم • أساليب تمويل التعليم.

مصادر تمويل التعليم ما قبل الجامعي في مصر. 


$$
\text { • - الدروس المستفادة. }
$$

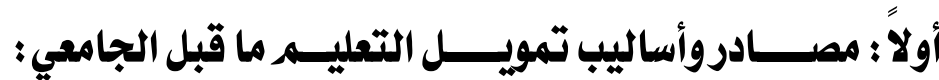

وقد تختلف وتتعدد أنواع ومصادر التمويل من دولة إلى أخرى فمن الصعب اختيار نمط تمـويلي معين فعمليـة اختيـار أي نمـط تمـويلي يعتمــ بصـفة أساسـية علي النظـام السياسـي والاقتصـادي والاجتمـاعي السـائد في الدولـة وعلي كل دولـة أن تختار مـا يناسبها في ضـوء ظروفها وإحتياجاتها. (๕)

ومن هذا المنطلق تعددت التقسيمات والتصنيفات التي وضعها الباحثون لمصادر تمويل

$$
\text { التعليم وذلك علي النحو التالي:(•) }
$$

1 -1التصنيف الأول لمصادر تموبل التعليم:

$$
\text { ب) أ) المصادر الحكومية . }
$$

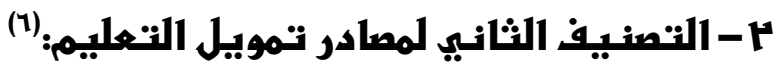
أ) المصادر الأساسية وتشمل التمويل الحكومي ب) المصادر الثانوية وتشمل مصادر داخلية ومصادر خارجيه

(v)

$$
\text { ج) أ) التمويل الحكومي المهود الذاتية }
$$

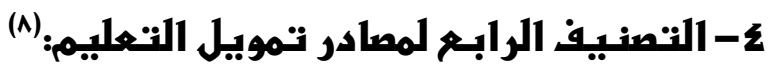
أ) تمويل التعليم من خلال الميزانية العامة للدولة ب) تمويل التعليم من خلال ميزانية القطاع المحلي ج) تمويل التعليم من خلال الأفراد د) تمويل التعليم من خلال المساعدات الخارجية 
ومما سبق نستتنج أنه هناك تنوع واختلاف في تقسيمات مصادر تمويل التعليم ولكننا

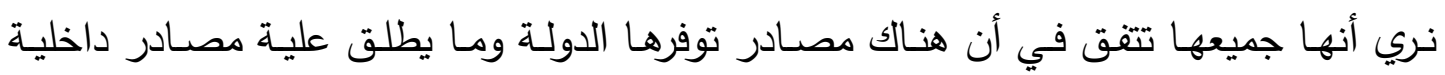
ومصادر أخري تأتي من الخارج في صورة منح وهبات وتبرعات وهي مصادر خارجية ومن هنا وفي ضوء ما سبق يمكن تقسيم مصادر تمويل التعليم في هذه الدراسة إلي:

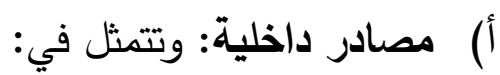

$$
\text { هالتمويل الحكومي. }
$$

ب) مصادر خارجية: وتتمثل في المنح والقروض والمساعدات الخارجية.

\section{المصادر الداخلية لتمويل التعليم:}

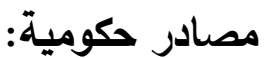

ويعبر التمويل الحكومي عن جملة ما تخصصـه الدول في ميزانيتها من التعليم حيث

تقوم الحكومات في أغلب الدول بتخصيص مبالغ معينه من الميزانية العامة للدولة للإنفاق علي مئري

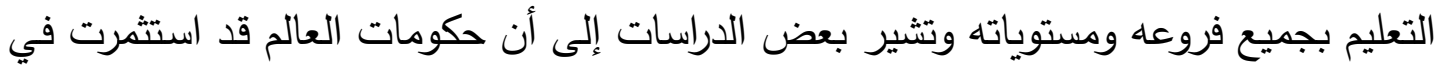

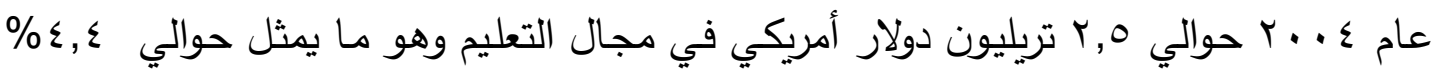

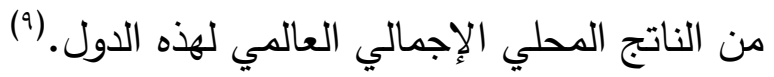

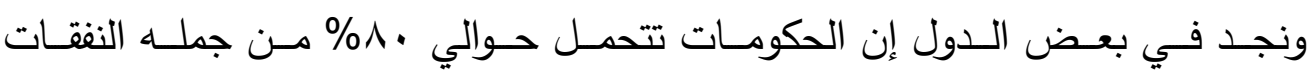
المخصصة للتعليم و تختلف من دوله إلى أخري فمثلا في جمهورية التشيك نجد أن الحكومة

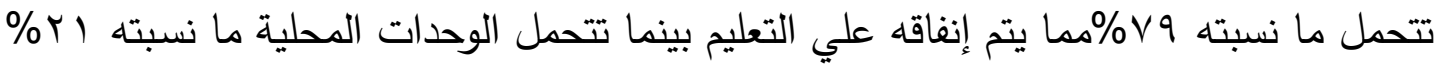
من جملة هذه النفقات.(1) وتعد فكرة التدخل الحكومي في التمويل فكرة اقتصادية علي أساس فشل السوق الحرة التعليمية في توزيع التعليم علي جميع الطبقات دون تحيز أو تمييز . (') وتؤكد الإحصاءات أن هناك فجوه كبيرة بين الدول في حجم إنفاقها علي التعليم بسبب إختلاف دخلها القومي وعلي الرغم من التباين فيما تتفقه الدول علي التعليم من بلد إلى أخر إلا لإني

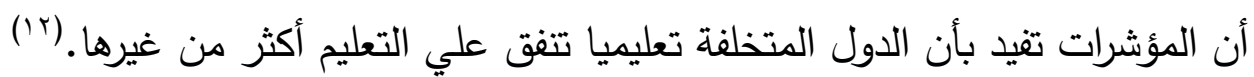


ويأخذ هذا التمويل صورا متعددة منها المصروفات التي تحصل من التلاميذ وغالبا ما يتم ذلك في مراحل التعليم بعد الإلزامي حيث تفرض الحكومة المصروفات علي تعليم التلاميذ في المدارس العامة وتغطي كل كلفتهم أو جزه منها وتلجأ إلى حث القادرين من رجال الأعمال والهيئات علي التبرع للتعليم بتقديم الأموال والأجهزة والمعدات وإقامـة الأبنيـة التعليميـة والتبرع بالأراضي أو الأجهزة والمعدات ويسمي هذا أحيانا بالجهود الذاتية. (rان)

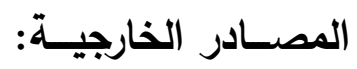

والمتمثلـة في المنح والقروض والمسـاعدات الخارجيـة، وقد تلجـأ الدولـة إلى مصـادر خارجية لتمويل عمليات إصلاح التعليم وتطويره وتحديثه وتقوم المنظمات الدولية بدور واضتح في هذا الثـأن ومن ذلك ما تقدمها هيئة اليونيسكو واليونيسيف كهيئتين تابعتين لمنظمة الأمم المتحدة لتقدمان مساعدات للتعليم تأخذ غالبا شكل المنح وهنالك منظمات أخري كالبنك الدولي كهيئة دوليـة وبعض الوكـالات الأخـرى منهـا وكالـة الولايـات المتحـدة للتميـة الدوليـة وتقـدم مساعدات للدول النامية ومنها مصر وكان التعليم من أهم المجالات التي لها نصيب من هذه المعونـات وتعتبر مصر من الدول التي لجـات إلى التمويـل الخـارجي لتحقيق تتميـة مجتمعيـة ولذلك لجات إلى مؤسسات دولية والدول المتقدمة للحصول علي هذا التمويل في صورة منح وقروض ولم يقتصر لجوء مصر إلى التمويل لدفع عجلة الإنتاج بل تعداه إلى الخدمات أيضـا حيـث تلقت مصـر مـنح وقـروض لتمويـل المشـروعات الأساسـية مـن ميـاه وصـرف صـحي واتصالات سلكية ولاسلكية ثم إلى الصحة والتعليم وذلك من خلال ما تقدمة المنظمات الدولية

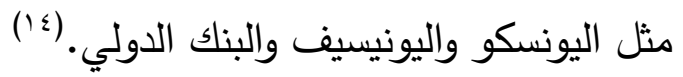

\section{ثانيا :الأساليب المختلفة لتمويل التمليه :}

تختلف الدول النامية عن الدول المتقدمة في الإنفاق علي التعليم وتمويله حيث تعاني الدول النامية من مشاكل مالية وعجز في الموازنات العامه وفي المديونية الخارجية التي تؤثر سلبا علي تمويل التعليم بها علي عكس الدول المتقدمة التي تتوافر لديها إمكانيات اقتصادية وموارد مالية كافية لمواجهة مشكلات تمويل التعليم كما إن الإنفاق علي التعليم يرتبط بتحقيق أهداف معينـة مثل تخفيض الأميـة وخلق حوافز للتقدم العلمي وغيرهـا وهذه الأهداف ينبغي 
التأكيد عليها عند تقييم التعليم وشأنه في ذلك مثل أي مشروع أخر لذلك ينبني إعطاء أوزان نسبية لمثل هذه الأهداف عند عملية التقييم. (10) وفي الحقيقة أن أهم مشكلة تواجه الدول عند تناول قضية تمويل التعليم هي مواجهة

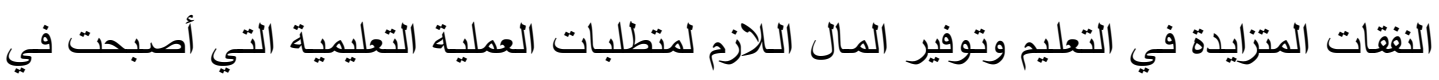

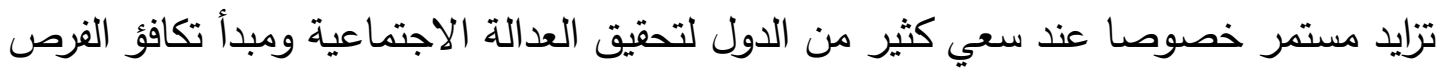

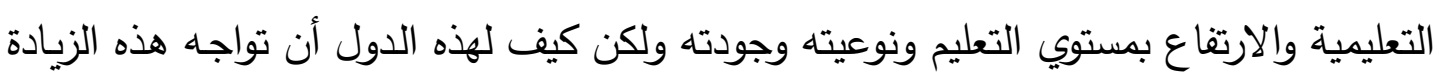

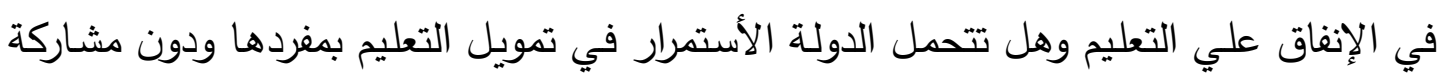

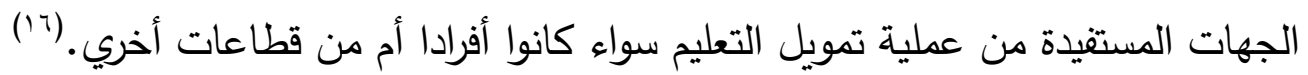
ويمكن تصنيف الأساليب التمويلية للتعليم وفقا للمحاور الاتية:

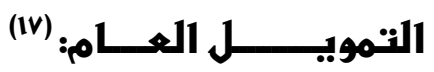

وفي هذا الأسلوب تتحمل الدولة تكاليف الإنفاق علي التعليم من خلال الموازنة العامة للدولة وتخصص ميزانية محددة للتعليم بهدف إتاحة الفرص التعليمية للجميع وتحقيق مبدأ تكافؤ الفرص والعدالة الاجتماعية وهذا الأسلوب يواجه انتقادات حادة بسبب تزايد الإنفاق علي التعليم

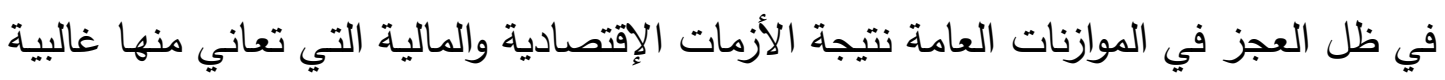

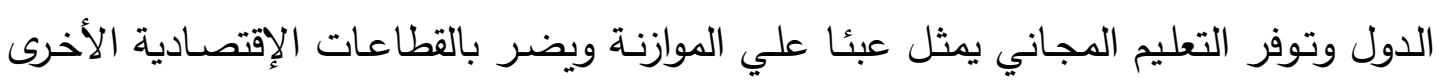
التي تؤدي كذلك إلى ضعف الكفاءة الإقتصادية للنظام التعليمي.

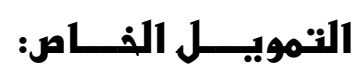

وهو صورة من صور التمويل تتمثل في تحمل الأفراد أوعائلاتهم دفع تكاليف تعليمهم عن طريق دفع الطلاب رسوما للخدمات التي يحصلون عليها من المؤسسات التعليمية ويري

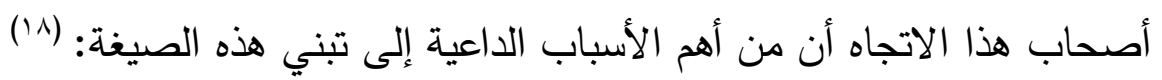

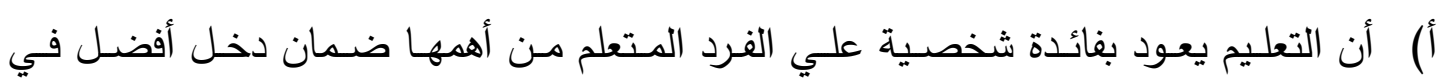

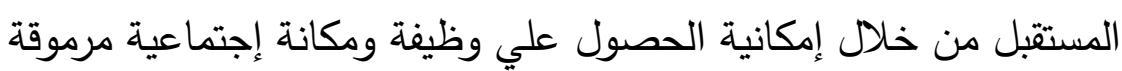

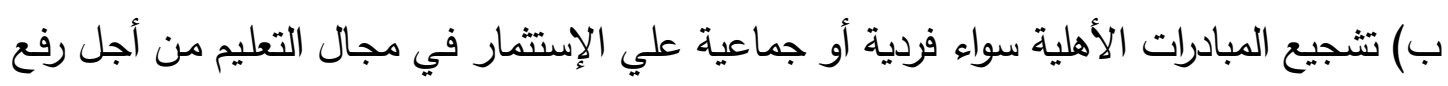
مستوي المؤسسات التعليمية وتوفير مدارس متميزة قد لاتستطيع الدولة توفيرها. 
ج) التغلب علي نقص الموارد المالية اللازمة لتسيير العملية التعليمية مما يساعد علي تحسين

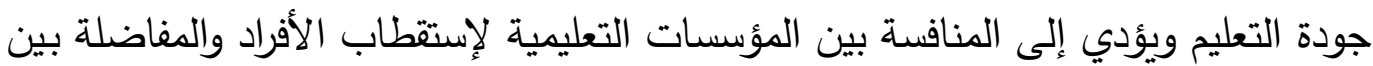

الخدمات التعليمية.

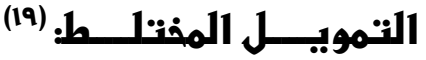

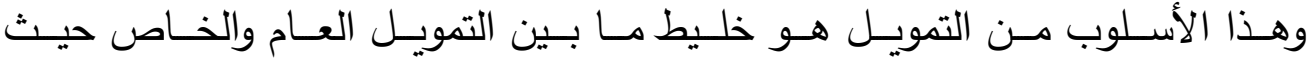

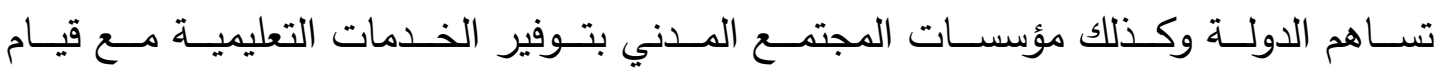

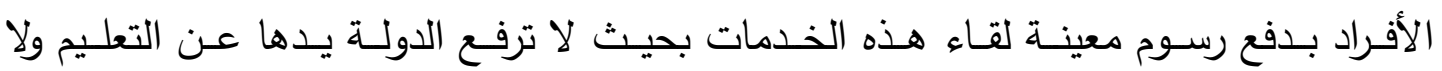
تدعه عرضه لمعايير السوق والتكلفة.

\section{ثالثا : مصادر تمويل التعليم ما قبل الجامعي في مصر}

ونجد أن تمويل التعليم في مصر يعتمد بشكل أساسي علي نسبة ما يتم تخصيصسه

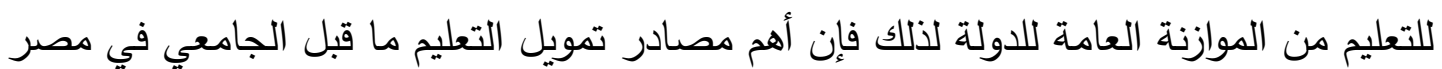
هو التمويل الحكومي بالإضـافة إلى بعض من المصادر الاخري المتمثلة في الجهود الثعبية والمصادر الخارجية المتمثلة في المنح والقروض وغيرها وسوف يتم التعرف علي هذه المصادر

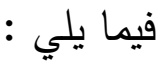

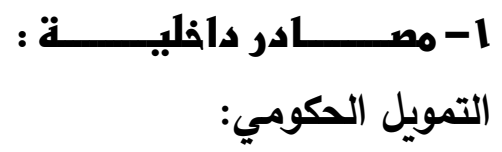

ومما لاشكك فيه أن الإعتماد الكلي للإنفاق الحكومي علي تمويل التعليم ما قبل الجامعي في في مصر يكون من ميزانية التعليم والتي تمثل الجهد النسبي للإنفاق علي التعليم وما توليها الدوله من عناية واهتمام به وقد درجت الحكومات علي تخصيص مبلغ معين من المال من موازنة

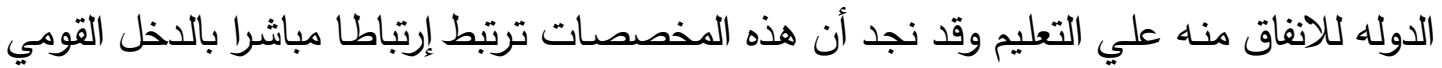
من جهة وميزانية الحكومة من جهة أخري لذلك تعتبر النسبة بين ميزانية التعليم وكلا من الدخل

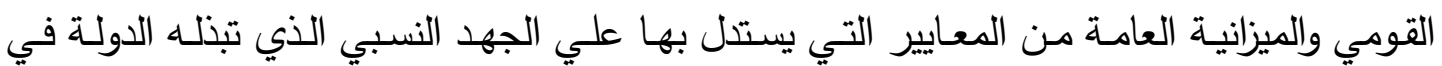

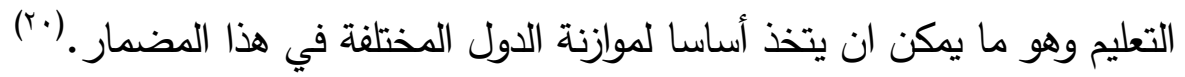
وتقسم ميزانية التعليم إلى ثمانية أبواب وفقا للتصنيف الاقتصادي للموازنة العامة للدولة والذي يقصد به تقسيم مصروفات الحكومة ومواردها وفقا لنوع الإنفاق وفقا للهدف منها (دفع الأجور - شراء السلع سداد القروض ..............) وتقسيم الموارد العامـة وفقا لمصـادرها 
(ضـرائب- منح- إيـرادات أخري .............) ووفقـا لهذا التصـنف يتكون كل بـاب مـن

الأبواب الرئيسية في جانبي الاستخدامات والموارد من مجموعة مختلفة من البنود يندرج تحت كل منها عدة أنواع والهدف من هذا التفصيل تتبع الإنفاق الحكومي إلى أدني المستويات الممكنـه بغيـة تفعيل الدور الرقابي علي الإنفاق الحكومي ونجد أن الصـورة الإجماليـة للموازنـة

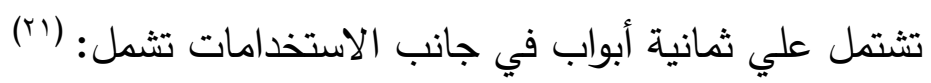
ا- الأجور والتعويضات ومكافأت العاملين - شراء السلع والخدمات

$$
\begin{aligned}
& \text { ع- الدعم والمنح } \\
& \text { r- الفوائد } \\
& \text { 7-شراء الأصول غير المالية } \\
& \text { 0- المصروفات الأخري } \\
& \text { 1-سداد القروض المحلية } \\
& \text { V- حيازة الاصول المالية والمحلية }
\end{aligned}
$$

\begin{tabular}{|c|c|c|c|c|c|c|c|c|c|}
\hline \multirow{2}{*}{ الجملة } & الباب الثامن & | الباب السابع | & الباب السادس & الباب الخامس & الباب الرابع & الباب الثالث & | الباب الثاني & الباب الأول & \multirow{2}{*}{ بيان } \\
\hline & سداد القروض & | حيازة الأصول & الاستثمارات & مصروفات أخري & دعمومنج & فوائد القروض & | السلع والخدمات & الأجور & \\
\hline IATrVoIr... & $899100 .$. & $1 . . .+1$ & $1890 \mathrm{V0} . .$. & 1.7rq... & ryora... & rV々17... & rYETYRY... & 1ะ7ar\&o.... & ir \\
\hline 19VAVYVY... & ororr... & • & VAlAsq... & $1.9+7 . . .$. & raq...... & rrrrq... & rrolr|s... & $178 v 1798 \ldots$ & $Y \cdots Y / Y \cdots Y$ \\
\hline rrAEAll-ErO & ror.A.... & - & irmargr... & rr.rqq.... & కrYIక... & rEY & rAYEsIq... & IArArigazro & $r \cdots \Lambda / r \cdots r$ \\
\hline rาะrrระ71... & v\&rav... & - & $1 r q 1.01 . .$. & irrqir... & ErrrA... & rrAar... & rranon $7 . .$. & rrrrgalı0... & $r \cdot \cdot q / r \cdots \Lambda$ \\
\hline rI & ro9or... & - & $1911407 . .$. & $|\varepsilon| 7 r \mid \ldots$ & \& $190 . .$. & rą.r... & rarsval... & 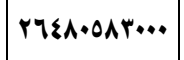 & $r \cdot 1 \cdot / r \cdot+q$ \\
\hline 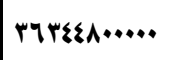 & VESYY... & - & rr.rAT\&... & lErryo... & \$709r... & rA.\&.... & r.109rq... & $r \cdot \wedge r \varepsilon \eta I T \cdot . .$. & $r+11 / r+1$. \\
\hline \&.rrYA10... & v7ara... & - & HIAYEAT... & lorsyr... & $0.097 \ldots$ & rrans... & rrarolo... & rron.A<Y... & $r+1 r / r+11$ \\
\hline 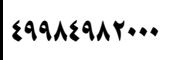 & Arr790... & - & $\leqslant \varepsilon 17 \cdot 19 \cdots$ & 10r797... & soryr... & rA^<0... & rquarrv... & 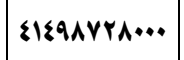 & $r+1 r / r+1 r$ \\
\hline 7r.97V & aro.r... & - & 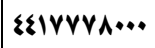 & I7raro... & osrqA... & rAAlY... & ralalql... & OETrITAT... & $r+1 \xi / r+1 r$ \\
\hline v§l & $\mid v \cdot \varepsilon+7+.$. & - & $\xi \cdot r \varepsilon \cdot 91 \ldots$ & TrraAr... & ograr... & ronlo... & rarossos... & Tororgor... & $r+10 / r \cdot 1 \varepsilon$ \\
\hline VY.V.orr... & 17910r... & - & roqะ\$0\&... & srAV.r... & $771.7 \ldots$ & rรYะr... & $\$ 819911 \ldots$ & Irragrao... & $r+17 / r+10$ \\
\hline
\end{tabular}

ومـن هـذا المنطلق تـم تقسـيم ميزانيـة التعليم مــا قبـل الجـامعي إلىى ثمانيـة أبـواب،

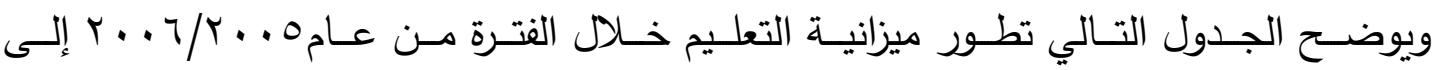

$$
\text { عام } 10
$$

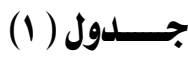

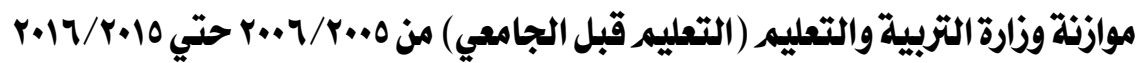

المصدر : وزارة التربية والتعليم. الإدارة العامة للمعلومات والحاسب الآلي .عام 10 • ب/ 1 ـ ب 
ومسن خـلال الجـدول السـابق نجـد انـهـ تـم توزيـع الميزانيـة المخصصـة للتعليم علي

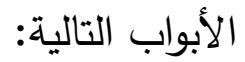

\section{ابألأول (الأجور)}

وقد خصص لله حوالي . . .

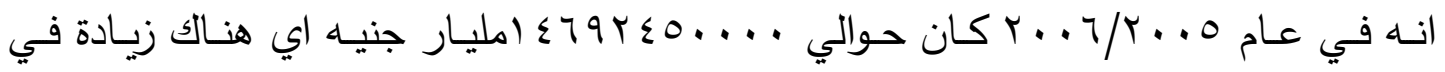

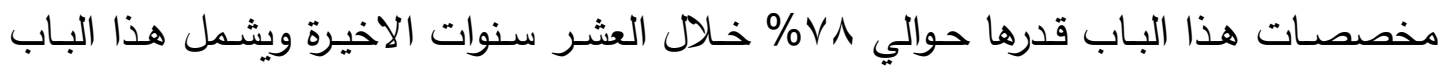
الأجور والمكافآت ومرتبات لعاملين في الوزارة علي إختلاف فئاتهم وأنواعهم ونجد أن هذا الباب

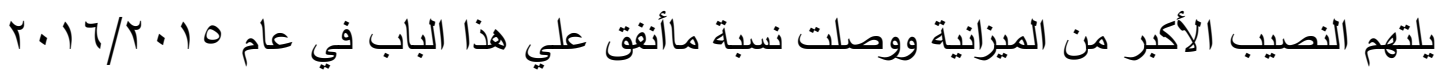
من ميزانيـة التعليم قبل الجامعي حوالي ^^^\% وقد يرجع ذلك إلى الزيـادة في أعداد المدرسين والعاملين في هذا المجال.

\section{ثانيا: البــاب الثانـــــي:}

وهذا الباب يشمل باب السلع والخدمات والتي تتمثل في الإيجارات والإنارة والكهربـاء ونفقات الطباعة وهذا الباب يمثل ^,ه٪من موازنه التعليم قبل الجامعي وقد خصص لـه حوالي

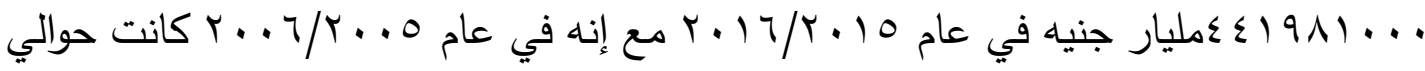
. . . . . .

\section{ثالثا: البـــاب الثالـــــث}

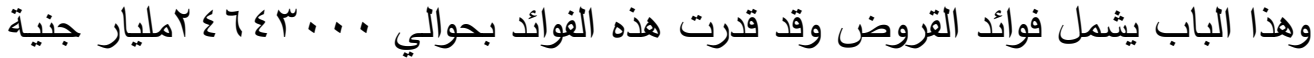

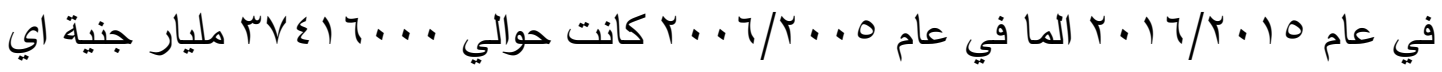
انخفضت قيمه الفوائد بنسبه ؟\%خلال العشر سنوات الاخيرة آى أن هنالك إنخفاض ملحوظ في قيمة هذه الفوائد وإن دل ذلك فإنـه يدل علي الإلتزام من جانب الوزارة بسداد الإقساط الخاصـة بالقروض في مواعيدها وقد بلغت نسبة ما ينفق علي هذا الباب من الميزانية حوالي ب\%من ميزانية التعليم قبل الجامعي.

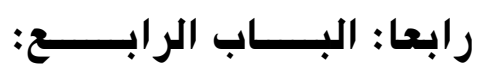

وهذا الباب الخاص بالدعم والمنح والمزايا كدعم الاشتراكات الطلابية والتامين الصحي للطـلاب ونجد ان هنـاك زيـادة في قيمـة الـدعم ففي عـام 0 . . ب/ ج . . ب قدر الدعم بحوالي

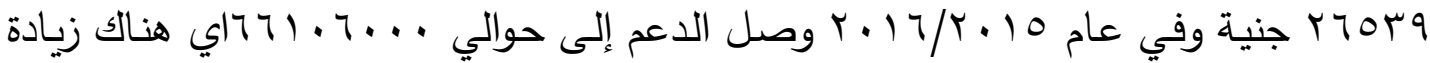


في مقدار الــعم بنسبة 90\%وقدرت قيمـة الإنفـاق علـي هـا البـاب مـن ميزانيـة التعليم بحوالي.^\% من ميزانية التعليم قبل الجامعي.

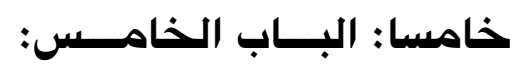

وقد تم تخصيص حوالى.0\% من ميزانية التعليم لهذا الباب الذي يشمل المصروفات

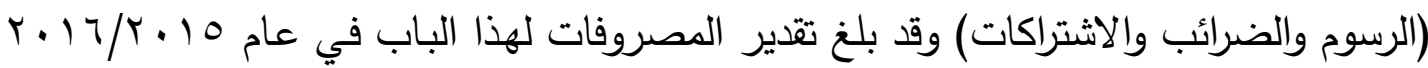

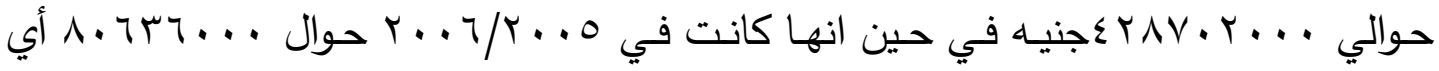
هنالك زيادة في مخصصـات هذا الباب خلال العشر سنوات الأخيرة مقدارها إي\% من قيمهـ موازنة التعليم قبل الجامعي.

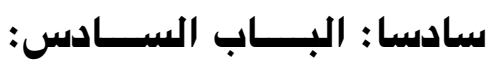

وهو يشمل الإستثمارات مثل المباني والأدوات المدرسية والمعامل وقد بلغت قيمة هذه

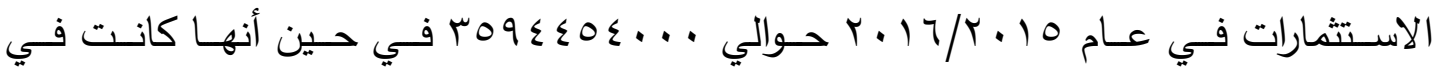

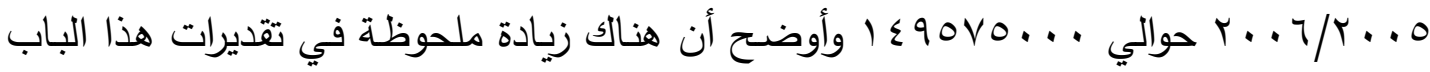

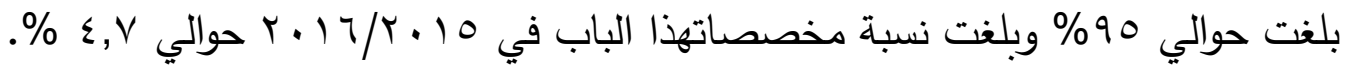

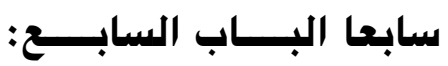
وهذا الباب لا توجد له أي مخصصات أو أو مبالغ في الميزانية وهذا الباب يشمل حيازة

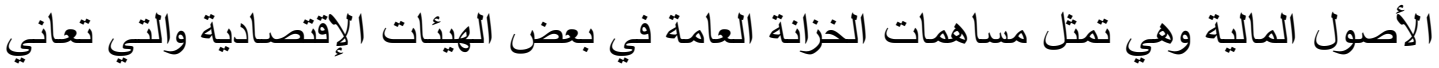

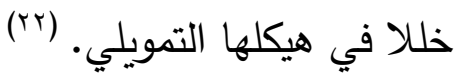
ثامنا: البـــاب الثامـــن

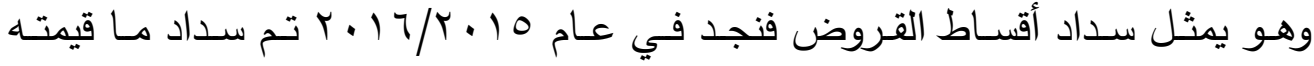

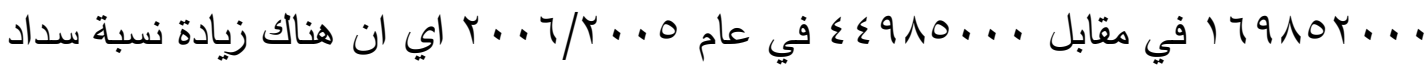

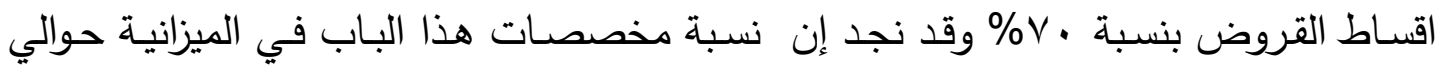
r r r من موازنة التعليم قبل الجامعي لهذا العام. ومما سبق نستنتج أن الباب الاول وهو الخاص بالأجور يلتهم معظم الميزانية حيث أنه

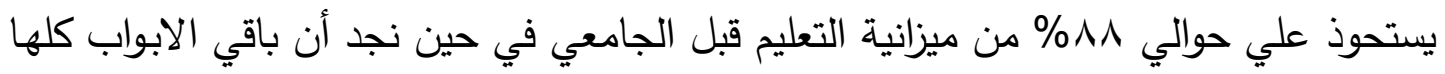

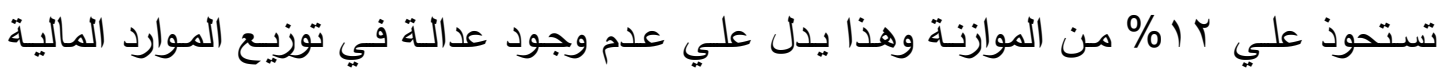

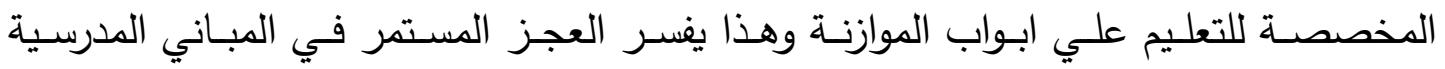


والخامات والتجهيزات خاصة في ظل الإرتفاع الملحوظ في كثافة الفصول حيث تستحوذ النفقات

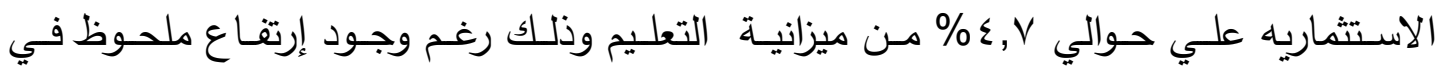

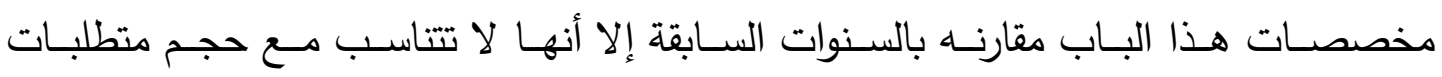

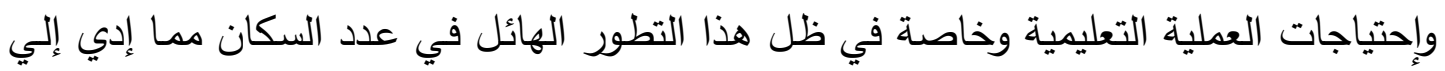
إرتفاع في معدلات الطلب علي التعليم • وخلئ

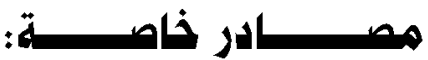

وهذه مـن المصـادر الهامـه للتمويـل حيث تثـمل نصيب التعليم مـن الهيئات غير

الحكومية والافراد ورجال الأعمال ويسمي البعض هذا المصد بالجهود الذاتية (rr)

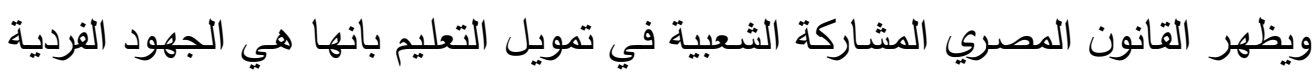
أو الجماعية أو المؤسساتية التي يقوم بها البعض في مجال التعليم كإنشاء المدارس وصيانيانها

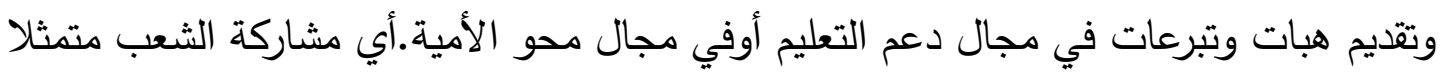

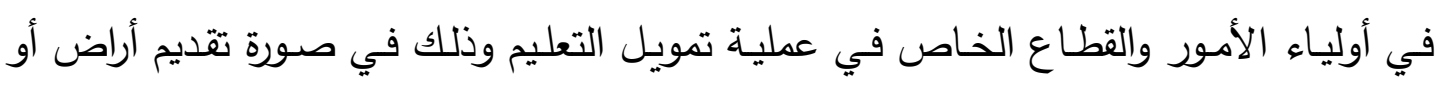

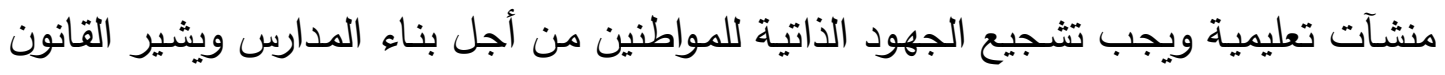

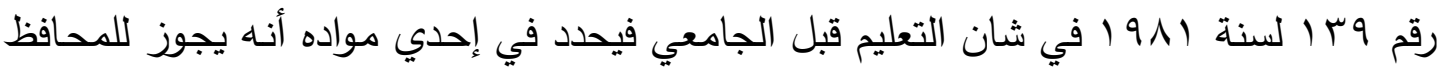
الافادة من الجهود الذاتية للمواطنين وفي تتفيذ خطة التعليم المحلية وبعد موافقة وزارة التعليم ويجوز أن يتضمن ذلك إنشاء صندوق محلي لتمويل التعليم بالجهود الذاتية ويسهم الأهالي في لتئي

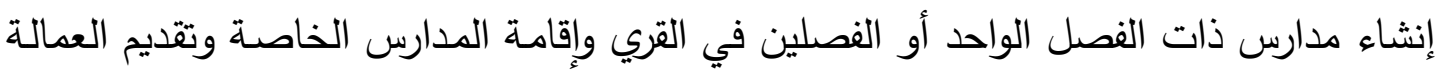

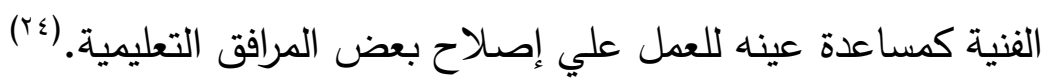

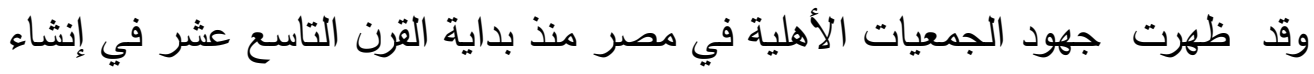

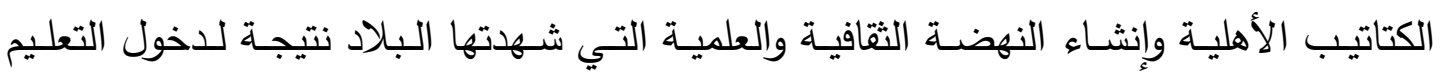
الحديث ولحركة البعثات العلمية بالخارج.(ro) وقد برز نشاط الجمعيات في التسعينات وذلك لتخفيض العبء عن الحكومة حيث نادت

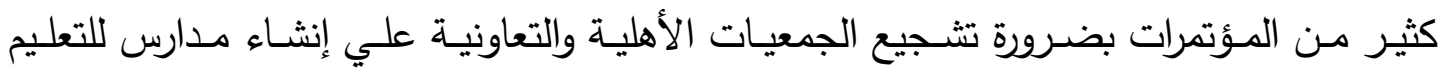
الابتدائي والثانوي وغيرها من المراحل التعليمية المختلفة بحيث يتوافر التمويل من خلال صيغة

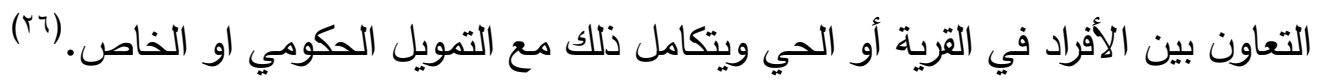


وقد برز دور المشاركة في مجال تمويل التعليم في المجتمع المصري بقيام الجمعيات

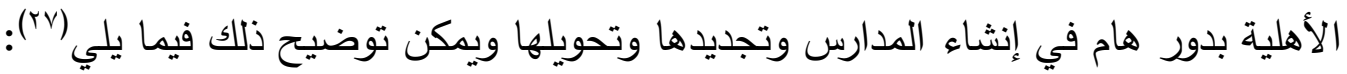

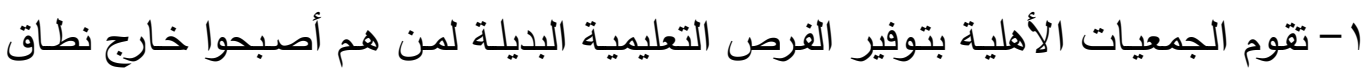

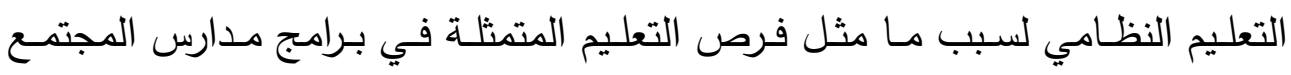
ومدارس الفصل الواحد الذي يقدم في الريف والمناطق النائية.

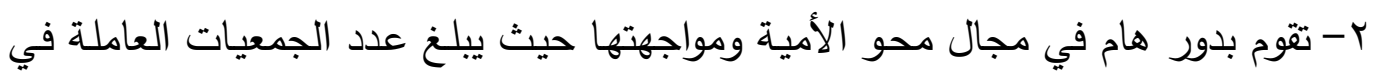

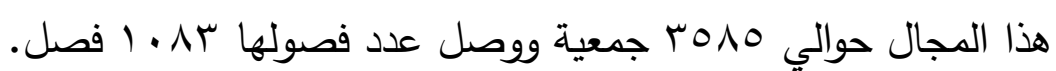

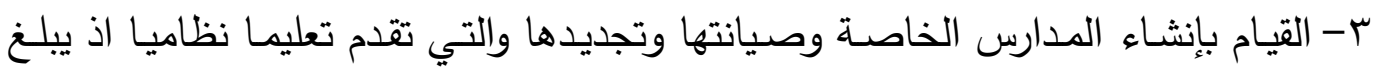

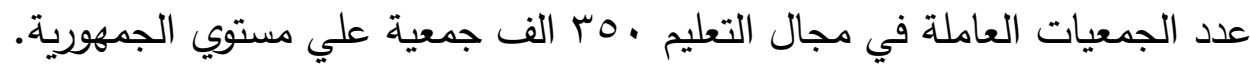
ع - دعم المدارس الحكومية القائمة بإصلاحها وترميمها وتزويدها بالأثاث وتدريب المعلمين ورفع كفاءة العملية التعليمية بها. 0- توفير فرص تعليمية مناسبة للأطفال ذوي الاحتياجات الخاصة.

\section{المصادر الخارجية لتمويل التعليم ما قبل الجامعي في مصر}

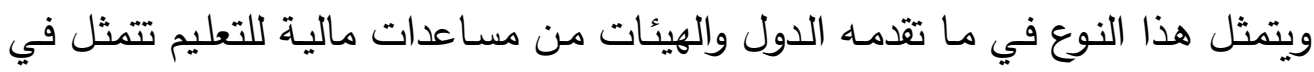

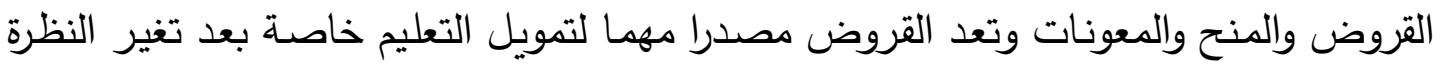

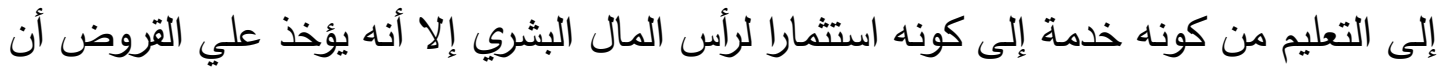

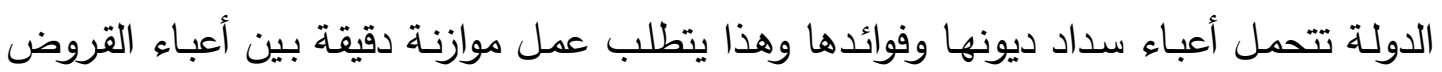

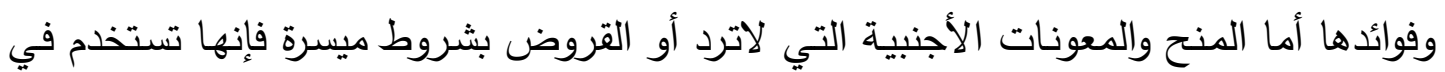

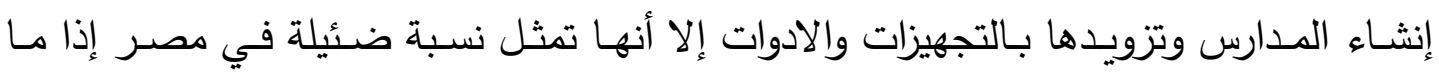

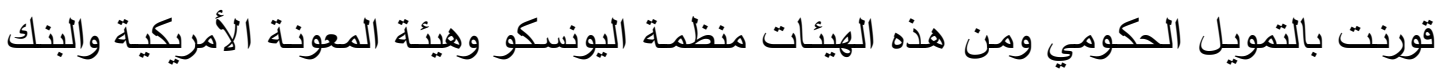

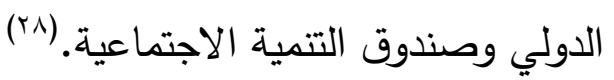
وسوف نركز هنا علي تحليل موجز للازمات المصاحبة لهذا المصدر التمويلي والمترتبة

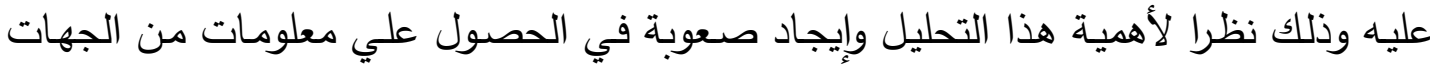
والمؤسسات المانحة وسوف نركز في هذا التحليل علي ابرز المؤسسـات وهما البنك الدولي وصندوق التتمية الاجتماعية. 


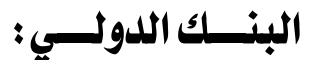

يعد البنك الدولي أحد المنظمات الدولية الذي يعتمد أسلوب العمل فيها علي تشخيص الأسباب الأساسية للمشكلة بواسطة خبرائه الذين يعملون ميدانيا خـلال بعثات ممتدة ويقدمون

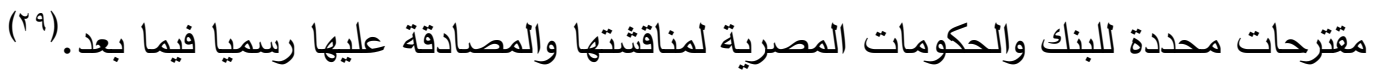
وتنقسم معونات البنك الدولي إلى منح وقروض ومعونات مالية وأخري فنية حيث تستند القوي الإمبريالية الجديدة المتطلعة إلى بسط نفوذها علي العالم بأسره وهي الولايات المتحدة الأمريكية ويتحكم من خلالها في إقتصاد العالم وخاصـة دوله الفقيرة فحكومة الولايات المتحدة الأمريكية بيدها القرار النهائي في اي من هاتين المؤسستين التابعتين للأمم المتحدة وهنا تكمن

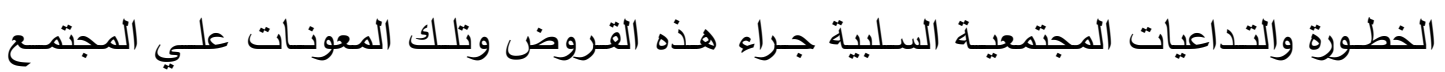
وإمكاناته وقدراته التنمويه وسياسته التعليمية. ونظرا لوجود مشكلات هيكلية ووظيفية بالاقتصاد المصري عهدت الحكومة المصرية بتطبيق برامج البنك الدولي خلال الثمانينات ويتضمن ذلك وجود عجز مالي مستمر بلـغ أكثر من 0 \% ومديونية قومية بنسبة ما يقرب من ابr\% من

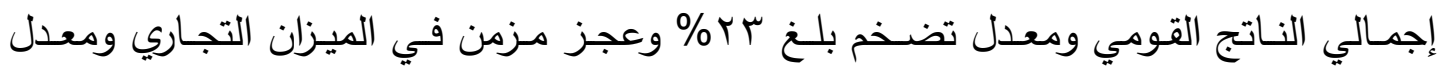
البطالـة وصـل إلـى ابr\% فضــلا عـن معـدلات ادخـار منخفضـة وكـان برنـامج الإصــلاح الاقتصادي والتكيف الهيكلي بمثابة إطار لتمويل الاقتصاد من كونه وسيله للإنتاج تملكها الدولة وتهيمن عليها إلى نطام تسوده الاعمال والمشروعات الخاصة ويتطلب ذلك تغييرات جوهرية في هيكل الاقتصاد ووظيفته وبما لها من مضمون ممتد وواسع النطاق اتجاه المجتمع.(·r) وقـد وضــع البنـك الـدولي عـدة مبـادئ لمشـروعية العمـل مـع الحكومــة المصـرية أن أن يـتم العمـل مـن خــلال الحكومـة المصـرية وبموافقـة الطـرفين علـي أن يخصـص التمويـل مـن خـلال عمليـة قوميـة للموازنـة شـريطة تتلقـي معظـم الأمـوال الأجنبيـة عبـر إتفاقيـات

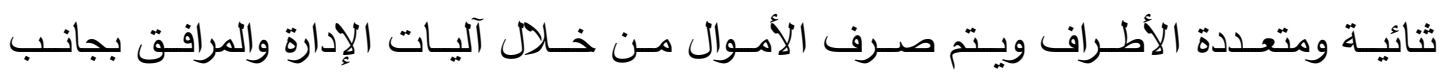
تمكين الدولـة الممولـة مـن إقتـراح وكالــة منفــهـ يصـرف لهـا التمويـل مـع مباشـرتها لكافـة

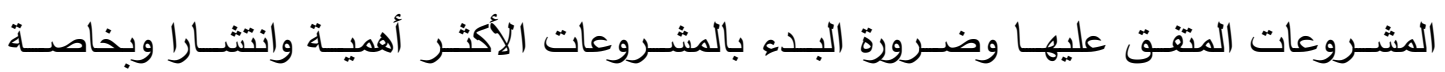

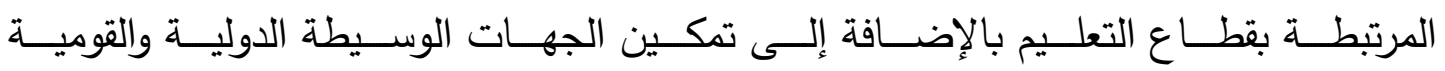
والمحليـة المعنيـة مـن النهـوض بالدور المحدد لهـا في تلقـي المسـاندة الخـاص بالقطاعـات وتخصيص الأموال وصرفها وتتفيذ المشروعات ومتابعة التنفيذ.(r)" 
وقد وضع البنك عدة شروط لتمويله التعليم المصري من بينها بيع المؤسسات العامة التي

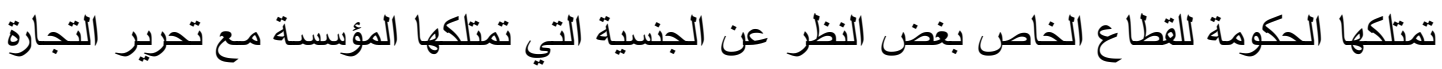

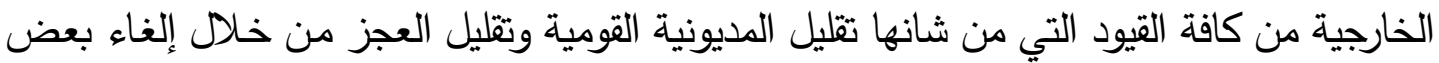

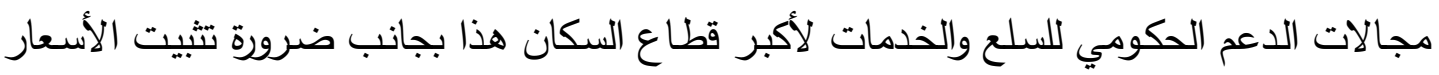

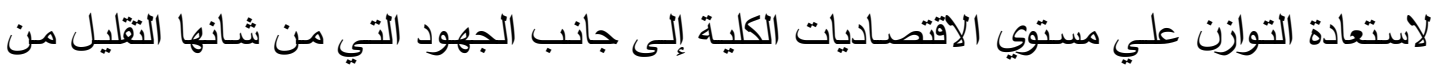
الآثار الجانبية المحتملة إلى الفقراء للحد الأدنى. (rr)

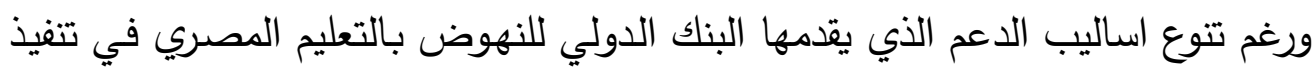
سياسته ورغم تأكيد البنك الدولي علي ان مصر من بين اربعة اسواق ناشئة من حيث معدل

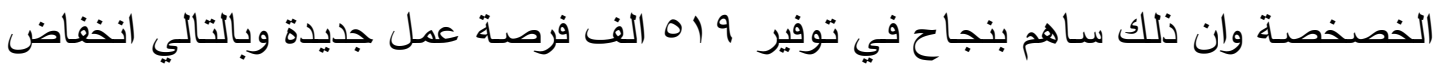

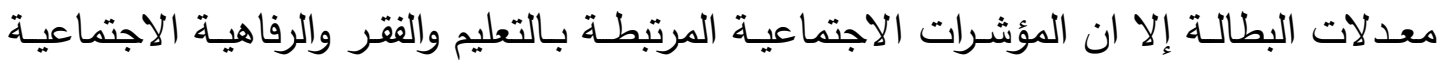
وقضايا النوع الاجتماعي والصحة مؤشرات الفقر تشير إلى ان متوسط نصيب الفرد من الناتج

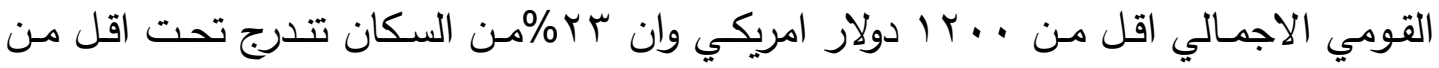

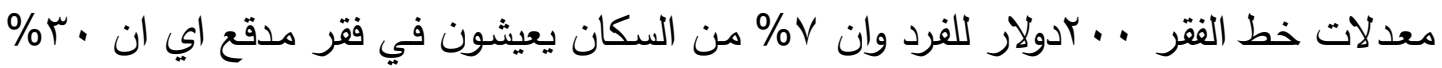

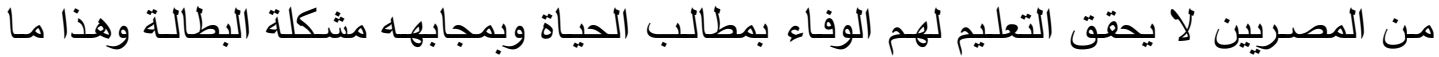

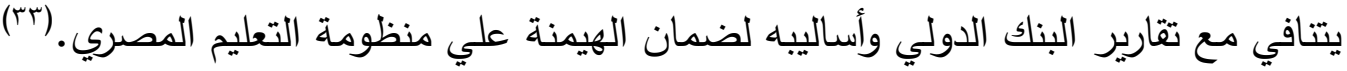

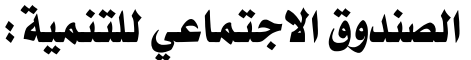

تم إنشاء الصندوق الإجتماعي للتتمية ليكون بمثابة منظمـة شبه مستقله تساعد في تخفيف المردود السلبي المرتقب لبرنـامج الإصـلاح الإقتصـادي والتكيف الهيكلي علي الفقراء والعاطلين وكان يتم النظر للصندوق باعتباره أحد مكونات شبكة الأمان الإجتماعية والتي كان من المقرر لها أن تستمر خمسة اعوام فقط ونظرا لنجاح الصندوق المعترف به فإنه الأن يبدأ

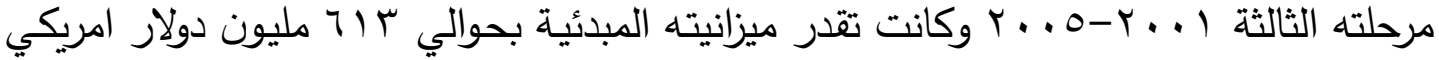
وصلت فيما بعد إلى V乏 مليون دولار أمريكي لفترة تتنهي عام 1997 وقد أسهم في هذه

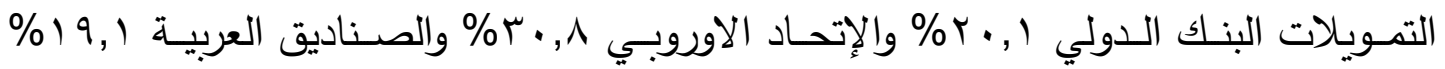
والحكومة الدصرية والدول الأخرى قد بدأت المرحلة الثانية عام \991 وإستمرت لعام ل ... وتبــغ ميزانيتها VVO مليون دولار أمريكي وخصص البنـك الدولي بالفعل ـ مليون دولار 
أمريكي لتمويل جزء من المرحلة الثالثة المرتقبة مما يشبر إلى أن هذه المنظمة قد تعدت كونها

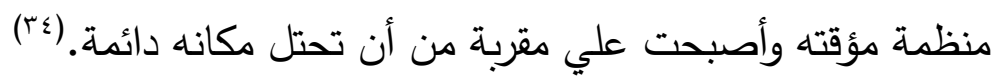

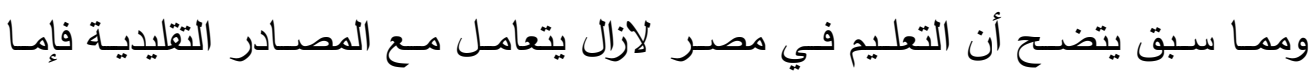
الحكومة وأمسا الإقتراض من الخارج والذي يؤثر بالطبع بشروطه علي نهضـة الدول وتقدمها وعدم قدرتها علي تحقيق أهدافها وقد ظهر أثر ذلك بالطبع علي نوعية التعليم وجودته ومن هنا بانيا كان لابد من البحث عن مصادر جديدة وبدائل جديدة للتمويل وايجاد سبل لمواجهة مشكلاته وترشيد النفقات وتوجيهه نحو الأهداف المراد تحقيقها الدروس المستفادة: أوضاع تمويل التعليم في مصر تكاد تكون سيئة للغاية وان السياسات التعليمية في لاهيل مصر غير فعالة ولا تعتمد علي استراتيجيات واضحة، كما تنتقد إلي الفاعلية ولهذا فإننا نطرح تصور مبسط بهدف تطويرها من خلال: أولا: الاستثمار الأمثل لنفقات التعليم

فالإدارة المالية الرشيدة يمكنها أن تعوض النقص في الموارد، بل تكون قادرة على تعظيم

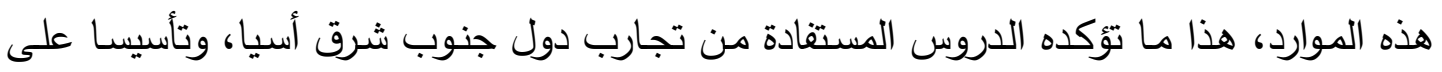
ذللك يمكن اقتراح مجموعة من الفاعليات منها: تقليل الهدر المتزايد في النفقات الحكوميـة من خـلال إتباع أسـاليب حديثة في بنـاء المدارس من خـلال إنثـاء المدارس بنظم وتصميمات جديدة وتوظيف الخبرات في التصميم والتنفيذ وتجهيز المدار، وإمكانية الوصول للمناطق النائية، وحل العديد من المشاكل المتعلقة بحيازة الأراضي المخصصة للمباني المدرسية. استخدام تكنولوجيا المعلومـات المتقدمـة في التدريس بما يعمل على تخفيض الكلفـة التدريسية. الاهتمام يرفع القدرات المهنية والعلمية للقيادات التعليمية وهيئات التدريس، والحد من التضخم الوظيفي والعمالة الزائدة في الوظائف الإدارية . . البحث عن مؤسسـات خاصـة تقوم بطباعة الكتب التعليمية تتـافس فيما بينها لتقليل تكاليف الطباعة وتحسين جودة المنتج. زيادة المخصصات المالية المخصصة للعملية التعليمية. 
"العمل على تحسين توزيع الموارد المالية بما يعيد التوازن، بين النفقات الجاريـة والنفقات

الاستثمارية، وبين المراحل التعليمية وفقا لأدوارها التتمويـة، وبين الريف والحضر بمـا

يحقق تكافؤ الفرص بين الجميع.

إنشـاء وحـدات اقتصـادية تــولى مسـئولية القيـام بدراسـات وبحـوث ميدانيـة وتحليليـة

وإستراتيجية وتقديمها لمتخذي القرار وصولا لقرارات سليمة اقتصاديا، وتحقق الأهداف

$$
\text { بشكل علمي }
$$

ثانيا: البحث عن مصادر جديدة للتمويل:

وتتطلـق هـذه السياسـات مـن كـون التعلـيم هـو " المشـروع القـومي لمصـر " الـذي

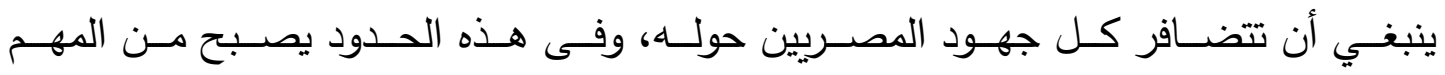

$$
\text { النظر في الإجراءات الآتية: }
$$

هإعادة النظر في تحديد الخيارات، وتتمية الوعي بتشجيع الأفكار الجديدة لتطوير عملية

التمويل من خلال الثفافية والمشاركة المجتمعية

إزالة العوائق أمام إسهامات رجال الأعمال في مجال إنثاء مؤسسات تعليمية تتنافس مافس

فيما بينها على تقديم خدمة متميزة .

تعظيم الاستفادة من المنح والقروض الدولية لاسيما المقدمـة من المنظمات الدولية بما

$$
\text { يتماشى وأهداف المجتمع. }
$$

" إعتماد صيخ جديدة لتمويل التعليم.

وضع خطة استراتيجية للتعليم واضحة المعالم ومحددة وغير مرتبطة بالمناصب. 


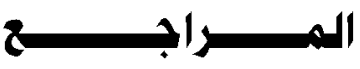

(1) Vivian Figueredo: Alternative Models for Secondary Education in Developing Contries: Rational and Realities, University of Pits Bargh, 2003, PP, 4-5.

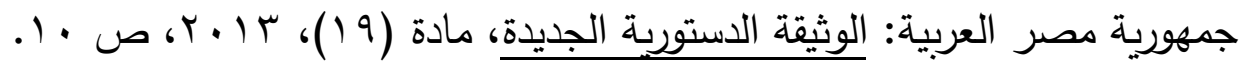

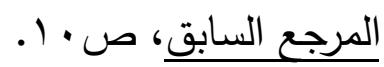

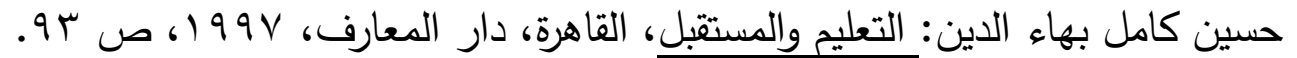

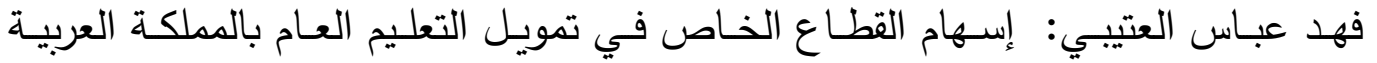

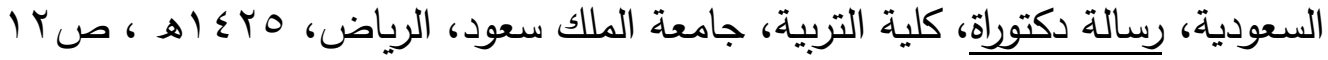

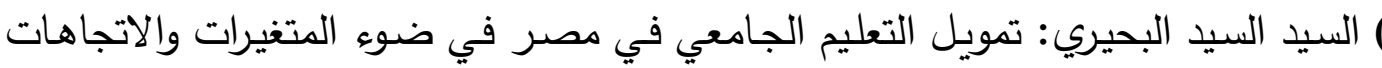

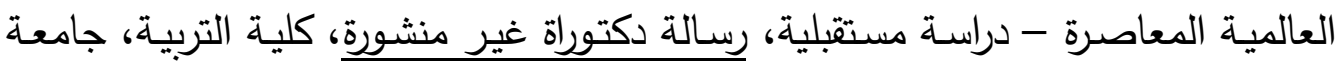

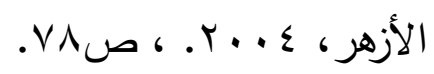

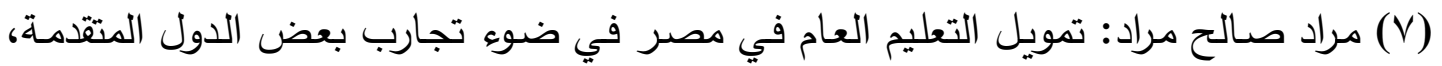

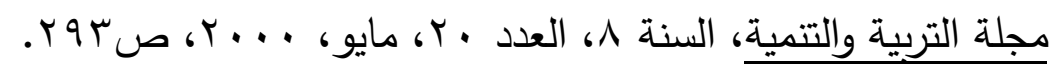

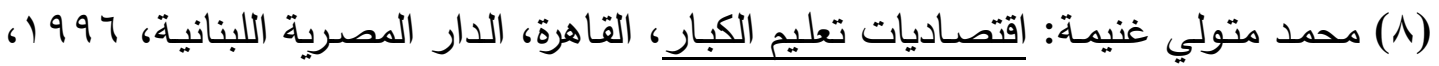
ص

(9) Jorge Saavedra* for the World Bank Institute Core Course Strategic Choices for Education Reform(2002):Op, Cit, P. 4

(10) OPCIT .P7

(11) OPCIT .P7

(Y (I) دغلاس وندهام: التربية للجميع (المتطلبات) الدراسة الثالثة لاجتماعات المائدة المستديرة

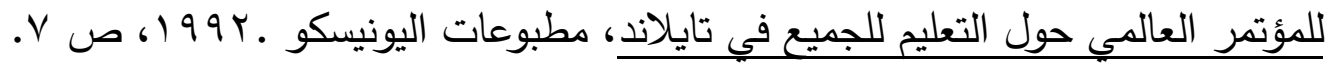

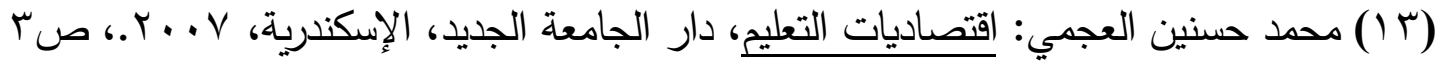

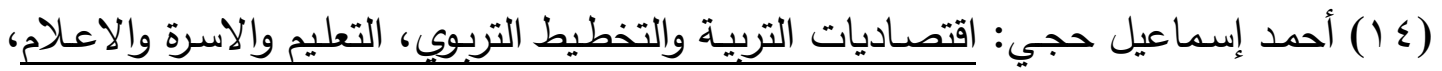

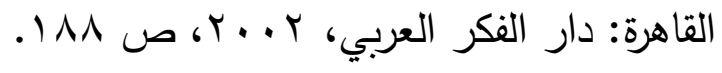

(10) المرسـي السيد حجازي: اقتصـاديات المشروعات العامـة، الدار الجامعيـة، الإسكندرية،

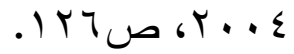

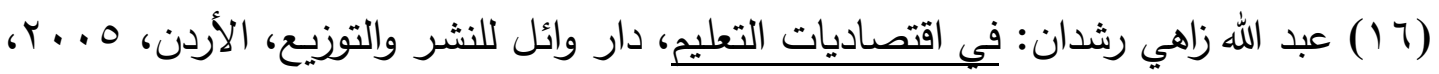

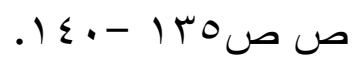

(Y) جان كلودأيشر : إعادة النظر في تمويل التعليم بعد الإلزامي، مجلة مستقبليات، مجلد (Y) (Y) (Y) 
(1) (1) فهد عباس العتيبي: مرجع سابق، ص 11)

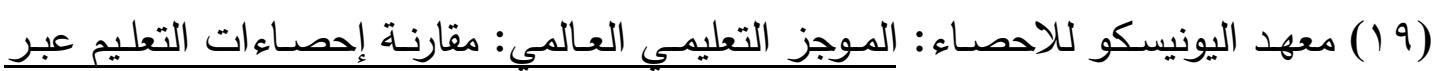

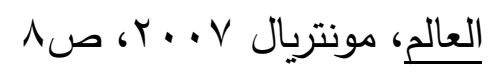

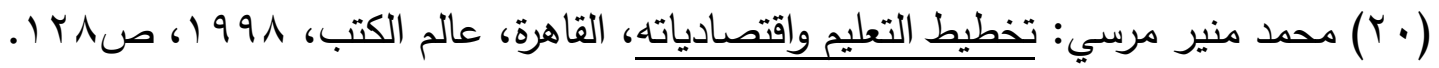

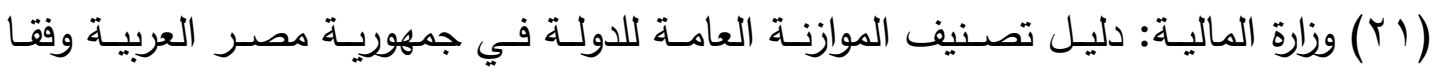

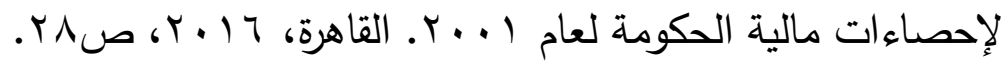

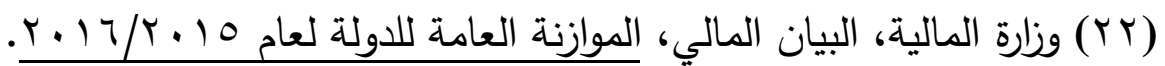

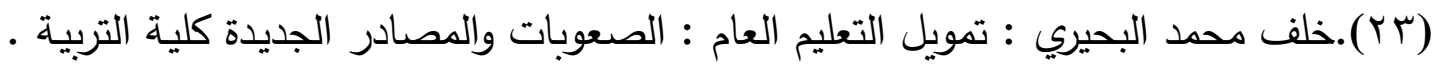

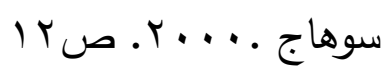

(Y) نبيـل عبد الخـالق متولي: دور المشـاركة الثـعبية في تمويـل التعليم، مستبتبل التربيـة

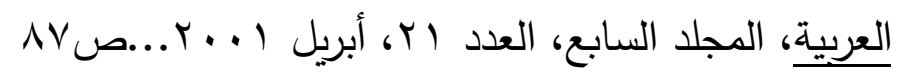

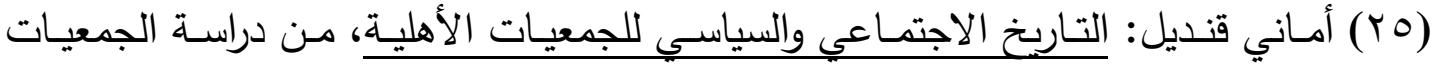

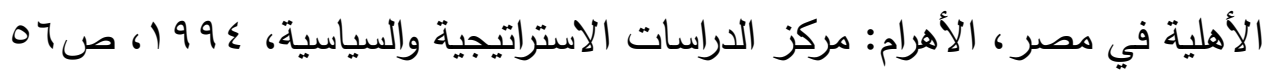

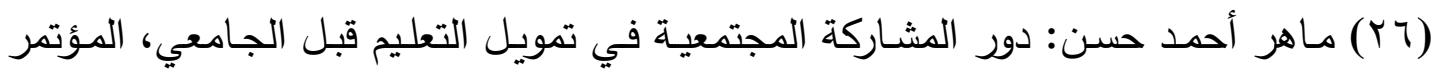

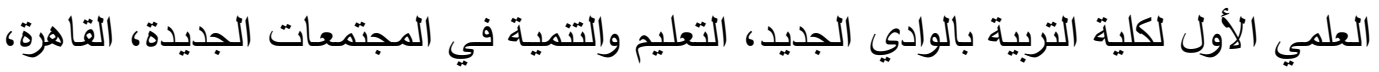

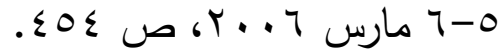

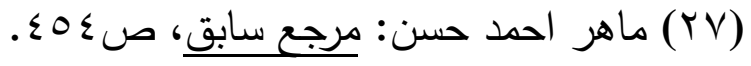

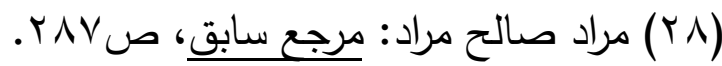

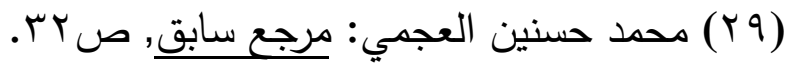

(30) World bank.: Staff appraisal report: Arab republic of Egyptsocial found project Washington, dc, World bank.1991.pp1-2

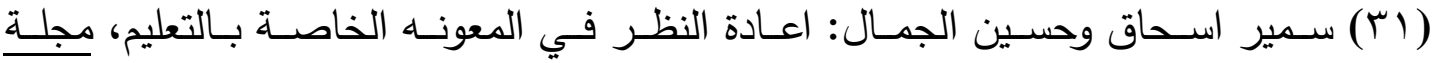

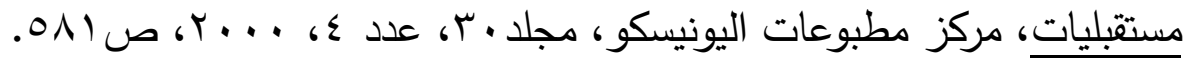

(32) World Bank: Staff Appraisal Report: Arab Republic of Egypt, Social found project Washington, dc, World bank. 1998.p7

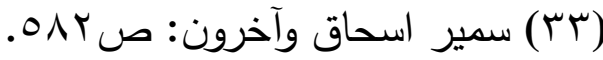

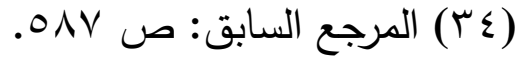




\section{Sources of funding for pre-university education in Egypt}

Abstract of the letter in Arabic Abstract of the letter in Arabic The study aimed to identify the sources of funding for pre-university education in EgyptAnd how to use them to serve the educational process through the identification of sourcesFunding for education.

Revealing new sources of funding. And to find out the reality of financing educationIn Egypt.

- To achieve the research objectives and answer the questions used descriptive approach The importance of research lies in its being Introduces sources of funding for pre-university education in Egypt.

- Emphasize the importance of funding sources as adevelopmentalinput in education. The most important results of the research are to reduce the increasing waste of government expenditure through the use of modern methods in building schools through the establishment of schools with new systems and designs, the use of expertise in design and implementation, the processing of schools, access to remote areas and solving many problems related to land tenure And the use of advanced information technology in teaching, which reduces the cost of teaching. The focus is on raising the professional and scientific capacities of educational leaders and teaching bodies, reducing occupational inflation and over-employment in administrative jobs, and looking for private institutions that print educational books to compete with each other to reduce printing costs and improve the quality of the product. 